\title{
O lugar da docência e do teatro na escola
} Spaces of teaching and the theater in school

Ricardo Carvalho de Figueiredo ${ }^{1}$ 


\section{Resumo}

Esse artigo discute o processo de constituição da docência a partir da inserção do licenciando em teatro na escola. Para isso a delimitação de um lugar para o desenvolvimento teatral com crianças e experimentações cênicas pelos licenciados se fez necessário por compreendermos que esse ato proporcionou a visibilidade da ação na escola e passou a revelar os processos de criação da cena, promovendo o contato do espectador com ensaios no próprio espaço escolar. Concluímos entendendo a necessidade da parceria com a escola para a formação do professor de teatro juntamente com o estabelecimento de um espaço para que o teatro se faça presente no cotidiano escolar, fazendo parte do processo de formação estética.

Palavras-chave: Pedagogia do teatro; teatro na escola; formação de professores

\section{Abstract}

This article discusses the central process of theater teaching with graduating students while they are living their initial experiences at school. The author searches for a definition of space for theatrical development with children as well as performing experiments created by the scholars. It was necessary to understand that the perfomances provided visibility while revealed the process of creating scenes, promoting the spectator's contact with the school's spaces. The author claims the necessity of partnerships in between University and school, so that the training of theater teachers establishes a performing space in everyday's school life, as part of an aesthetic educational process.

Keywords: Theatre pedagogy; theatre schooling; teacher's training. 


\section{Para situar a experiência}

Influenciado por minha história de vida e os desdobramentos oriundos das oportunidades e encontros tidos durante minha graduação ${ }^{2}$ venho compreendendo que a formação do professor de teatro precisa ser ampliada para além da universidade, estabelecendo parcerias na coformação do professor para lidar com a educação na contemporaneidade.

Sob esse ponto de vista, o de romper os muros simbólicos que separam a universidade da dinâmica da vida, venho coordenando o projeto de extensão universitária intitulado "Teatro-Educação: experimentos teatrais na Educação Infantil" desde o ano de 2010. Propus a criação de um projeto que pudesse aproximar a produção de conhecimento em ensino de teatro, elaborada no âmbito acadêmico, do teatro realizado na escola de educação básica. Esse diálogo me interessava por almejar que a formação do professor devesse se dar no vínculo entre universidade e escola e por ter como hipótese que a participação em um projeto pudesse questionar a fragmentação dos saberes disciplinares, buscando uma integração dentro do próprio teatro. Ou seja, se durante as disciplinas do currículo da licenciatura em teatro, o aluno tem matérias que priorizam ora o trabalho do ator, ora o trabalho do diretor e assim sucessivamente, na escola de educação básica, o professor de teatro precisa fazer teatro com seus alunos tendo como foco o próprio ato de conceber e ensinar teatro.

A aproximação da universidade com a escola/comunidade, imprescindível a um projeto de extensão, me interessava, por permitir e incentivar a inserção de licenciandos no âmbito escolar, o que poderia contribuir para um aprofundamento em sua formação como professor de teatro, pois estaria aprendendo a profissão no próprio exercício da docência em teatro. O professor se formando na e pela prática docente.

Desse modo, apresento a seguir como tenho proposto a formação do professor de teatro que passa pela experiência - fundamental para a provocação de uma afet(a)ção e deslocamento dos saberes adquiridos no processo de formação docente.

\section{Algumas inquietações}

Faz algum tempo que tenho me perguntado sobre o modo como se dá o aprendizado em teatro. Tem me interessado compreender como esse saber, praticado dentro de um contexto e originado da própria cultura humana, foi capturado pela escola e se transformando em um objeto de ensino. Entendo que o teatro é uma forma de expressão (artística) e está presente desde as nossas primeiras brincadeiras de faz de conta.

Concordo com os autores da "teoria da forma escolar" (Vincent, Lahire e Thin, 2001, p. 13), que nos apresentam que durante os séculos XVI e XVII, , "aquele que aprendia, fazia a aquisição do saber ao participar das atividades de uma família, de

${ }^{2}$ Conforme explicitado no Capítulo 1 da tese de doutorado intitulada "Percursos de aprendizagem da docência em teatro a partir do próprio ato docente" (Figueiredo, 2014). 
uma casa. [...] aprender não era distinto de fazer" (Grifos meus). Se aprender não é distinto de participar da ação em si, como podemos, enquanto formadores de professores, pensar-agir em novas formas de praticar a formação do professor de teatro, não dicotomizando a formação teórico-prática?

Há, nessa proposição, o princípio de que aprender independe da existência da relação mestre-aprendiz e da instauração de uma relação propriamente pedagógica (Lave e Wenger, 2003). Os saberes não residem, portanto, em quem ensina e sim, na organização da prática social da qual quem ensina e quem aprende são partes.

Nesse contexto, aprender não é sinônimo de adquirir algum conhecimento sobre determinado assunto, mas aprender resulta de um processo de participação e advém das experiências vividas coletivamente, corporalmente. Por ser inerente à prática social, a aprendizagem acontece prescindindo de situações de ensino e é pelo envolvimento na prática que surgem as possibilidades de aprendizagem.

\section{A experiência por si mesma}

Como havia de nossa parte o interesse em proporcionar às crianças uma aproximação com a linguagem teatral a partir do contato delas com as cenas produzidas pelos licenciandos, discuto a seguir essa relação do espectador com a cena, visto que os licenciandos buscavam trazer, em seus ensaios ${ }^{3}$ realizados na escola, elementos de teatralidade experimentados com as crianças em sala. Ou seja, havia em nossa proposição um duplo movimento: os licenciandos experimentavam aspectos teatrais em um processo criador entre si e ao mesmo tempo elaboravam modos de propor esses experimentos às crianças, em um processo de retroalimentação, da experimentação cênica para a sala de aula e vice-versa.

Várias ações visam sistematizar uma pedagogia do espectador e têm sido cada vez mais praticadas por grupos teatrais que oferecem como contrapartida social um desvelamento de seu processo artístico para os espectadores, ou através de ações culturais pontuais gestadas por associações diversas que voltam seu olhar para o espectador. Em pesquisa recente sobre o período de uma década do Programa Municipal de Fomento ao Teatro da cidade de São Paulo, Maria Lúcia Pupo (2012) faz um minucioso estudo sobre as oficinas oferecidas pelos grupos contemplados com o programa. A pesquisadora traz como questões pertinentes à investigação se há ou não vínculos "diretos e recíprocos entre a oficina e o acontecimento cênico projetado pelo coletivo" (Pupo, 2012, p.49) e a existência de "alguma expectativa de que os frequentadores das oficinas exerçam influência efetiva na criação." (idem). Em sua análise, chega à conclusão de que existem modos diversos de realização dessa contrapartida, desde grupos que buscam a transmissão de um determinado saber conquistado pelo coletivo, passando por grupos que não estão interessados em transmitir um saber, mas "riscos a serem corridos juntos" (Pupo, 2012, p.52) e por fim, grupos que privilegiam "a disseminação de meios que propiciem a multiplicação de fontes de

\footnotetext{
${ }^{3}$ Os ensaios aconteciam no espaço de arena existente na escola - conforme apresentaremos a seguir. Como a professora das crianças estava trabalhando com um projeto de conhecimento e resgate de brincadeiras populares, os licenciando deram início à pesquisa cênica a partir de seu próprio repertório vivencial sobre a temática e observações nas aulas com as crianças, do que brincavam durante os intervalos e recreio.
} 
criação artística" (Pupo, 2012, p.53).

Falar da relação entre espectador e cena em nosso projeto é muito significativo. Primeiro porque foi a partir do interesse em pensar em uma formação do espectador para o teatro desde a infância que propus o início dessa caminhada. Mas não apenas, pois veio junto desse interesse elaborar uma proposta extensionista, onde o licenciando em teatro, exercitando o seu papel de professor-artista ${ }^{4}$, pudesse, além de fazer teatro na escola, provocar experimentos teatrais junto das crianças no espaço escolar. Teatro e ensino não seriam dissociáveis.

Assim propus que os ensaios das cenas não fossem realizados mais fora da Unidade Municipal de Educação Infantil (UMEI) Alaíde Lisboa, como ocorreu no primeiro ano do projeto. Esses ensaios ocorriam em uma sala do curso de graduação em teatro onde havia um espaço adequado para o acontecimento, reserva de sala, acesso a figurinos, aparelho sonoro. Era preciso descobrir espaços na escola onde fosse possível experimentar propostas teatrais que aguçassem a criação e dessem visibilidade do projeto às professoras e crianças que não participavam dele, já que os licenciandos desenvolviam a prática teatral apenas com uma turma de crianças de quatro anos de idade. O espaço poderia trazer elementos para a elaboração da cena? Ensaiar no espaço escolar estava sujeito à interferência das práticas das crianças que poderiam estar presentes como elementos de fissura no processo e então, os licenciandos teriam que aprender a lidar com elas.

O entusiasmo do olhar das crianças espectadoras influenciou na escolha do espaço onde a cena foi apresentada pelos licenciandos. As improvisações se davam inicialmente em diversos espaços da UMEI e tanto a reação das crianças quanto a permanência delas nos espaços experimentados pelos licenciandos ajudaram na decisão do espaço da arena, tal como relatado por Charles:

Até esse momento havíamos ensaiado em espaços diversos como o parquinho, em cima do gaiolão e o pátio que havia perto da sala da Patota. Quando experimentamos a arena do gaiolão decidimos que ali seria o nosso espaço fixo. A decisão veio a partir das reações das pessoas que passavam e assistiam ao ensaio. Vimos que o ensaio naquele local renderia bons questionamentos para o projeto. (Charles - Caderno de campo) $)^{5}$.

Diante dessa proposta, o grupo de licenciandos começou a experimentar ações cênicas no espaço da arena. Ensaiavam ali sempre no final da manhã, após o encontro que realizavam com a turma de crianças.

No momento dos ensaios vários episódios ocorriam, visto que, como a arena é um espaço aberto e próximo à portaria de entrada/saída da escola, era um convite às crianças e adultos, a dar uma espiada naquele acontecimento.

O interessante é que esse exercício de abertura dos ensaios aos espectadores/ transeuntes foi se tornando um hábito para algumas crianças e turmas. Algumas professoras aproveitavam o momento dos ensaios para trazer as crianças, que ficavam

\footnotetext{
${ }^{4}$ No decorrer do texto opto pela expressão professor-artista, pois considero que o papel do professor de teatro é em si criador, ou seja, o professor compartilha e conduz na escola, a criação em teatro junto dos alunos.

${ }^{5}$ A partir de agora trarei trechos do caderno de campo para compor o texto. Além de mim, coordenador do projeto, serão apresentados relatos de Bruno Pontes, Charles Valadares e Gabriella Lavinas, integrantes do projeto como bolsistas de extensão.
} 
observando atentas ao que era construído/desconstruído pelos atores. Já outras tantas crianças, que ficavam esperando algum adulto buscá-las para irem embora, permaneciam atentas aos jogos improvisacionais que ocorriam. Recortei do meu caderno de campo uma observação desse evento:

As crianças de várias turmas passam para ir a outro espaço da escola e sempre param para ver o que acontece. $\mathrm{O}$ adulto (professora) faz com que deixem a área de interesse, cumprindo o objetivo proposto. As crianças da turma Patota (única turma que faz aula de teatro com os licenciandos) entram na cena, dada a intimidade com os atores/personagens. (Ricardo - Caderno de campo).

Artista é alguém desconhecido? De longe? Aqui não! Ele é professor-artista, está junto. Percebi que essa ação, a de ensaiar cenas em espaço aberto, junto das crianças, ajudou para desmistificar a ideia de que um artista é alguém que tem dom ${ }^{6}$, ou seja, não precisa fazer nenhum esforço para produzir seu trabalho. Desse modo, os atores simplesmente estavam exercitando o seu ofício com todo o esforço possível, suando, rolando no chão, errando, discutindo propostas, tentando afinar a sintonia para jogarem juntos.

O fato de os atores serem figuras conhecidas na escola, por transitarem ali dia a dia, era outro elemento fundamental para essa desconstrução da ideia romântica e elitista de artista, diversas vezes mencionadas pelas professoras da escola. Desvelar os mecanismos de elaboração da cena teatral era um esforço cotidiano para o grupo, visto a novidade da proposta na escola. Logo, a capacidade de concentração e abstração dos desvios da cena era imensa. Afinal, como ignorar a passagem, por diversas vezes no local da cena, de uma mesma criança? E continuo minha observação daquele dia:

\begin{abstract}
Os pais vão chegando para buscar as crianças. Muitos param para ver o ensaio. Permanecem o tempo que podem. Talvez uns segundos a mais, dada a estranheza da proposta: um ensaio de teatro na escola. Algumas crianças esperam os pais com mochilas, vendo o ensaio, quietas. Outras crianças acompanham a música, dançando. [Escravos de Jó]. De repente aparecem três professoras, cada uma empurrando dois carrinhos de bebês e atravessam o espaço com a atenção voltada para a cena. Sentam em frente à cena, enquanto olham os bebês. (Ricardo - Caderno de campo).
\end{abstract}

A proposta de realizar os ensaios no espaço escolar tem a ver com um desvelamento do trabalho, possibilitando às pessoas que conheçam minimamente como se dava a elaboração teatral daquele processo. Além de ser um laboratório rico para os atores, por terem as crianças como partícipes das opções cênicas. A comunidade escolar é atravessada por ações teatrais. Assim, o teatro não precisa vir com dia e hora marcado, enquanto evento nas festividades escolares. Ele está na escola, faz parte

\footnotetext{
${ }^{6}$ Kátia Bueno (2000) investigou as origens e usos dos termos: dom, vocação, aptidão e habilidade, quando usados no contexto da arte. Para a autora o senso comum usa esses termos como sinônimos e dentro da concepção essencialista, que tem caráter: inatista, determinista e naturalizado, em suas duas vertentes - divina e biológica/genética - faz-se muito presente, no senso comum, quando se busca compreender a existência de uma habilidade qualquer, sendo o modo de explicação mais corriqueiro. "Pensa-se que as habilidades podem aparecer espontaneamente, que o que se vê é a manifestação de algo que já era possuído naturalmente. Acredita-se que os contextos são apenas elementos estimulantes, canteiros onde pode brotar a semente escondida. As habilidades são vistas como 'Belas Adormecidas' que um dia poderão brotar' (Bueno, 2000, p. 18).
} 
dela e compõe o currículo da Educação Infantil.

Por mantermos os ensaios na escola durante alguns meses, acreditávamos que a repetição poderia ser enfadonha às crianças e que elas abandonariam o local. Ao contrário do que imaginávamos, além de se fazerem presentes durante vários ensaios, as crianças davam palpites durante os mesmos, como observou Bruno:

Para as crianças, tudo era novo sempre. Algumas vezes reclamavam, pois já tinham assistido, queriam outras coisas. Outras vezes riam do que já havia sido mostrado. Por vezes até participavam ativamente dos ensaios/apresentações, eram espectadores ativos: invadiam a cena, corriam conosco, pegavam as frutas que caiam, ora nos entregavam, ora saíam correndo com elas. Já as professoras, algumas vezes tentavam conter os ímpetos das crianças. Mandavam somente assistir, o que por vezes não funcionava, ou pedíamos para deixar que participassem. Outras vezes ficavam só na observação mesmo, com olhos atentos, desconfiados, com medo, surpresas, alegres (Bruno - Caderno de campo).

Para o espectador criança, o ensaio é cena. É o que constata Gabriella após o convívio com as crianças durante os meses de ensaios na escola. Se para os atores aquele procedimento de ensaio é uma parcela de elaboração da cena, para as crianças, era a própria cena. Para a criança ensaiar é apresentar.

Nosso exercício, treinamento, processo criativo (em andamento e construção) desnudava-se aos olhos das crianças como algo já pronto para ser visto. Aquilo que acontecia diante dos olhos deles, para eles, já era cena. Mesmo sem figurino, maquiagem ou aparelho de som, tudo já se fazia teatro (Gabriella - Caderno de campo).

Se nosso intuito era trazer outro modo de se relacionar com o teatro, conseguimos não apenas despertar a curiosidade dos pequenos, como das professoras, que são responsáveis, no ambiente escolar, por apresentar as modalidades culturais às crianças na escola. Assim, nesse mesmo dia Charles trouxe outro relato sobre a importância e impacto de um ensaio para a modificação e estranheza do cotidiano escolar. Vejamos:

Duas professoras se aproximaram também e perguntaram o que iríamos fazer. A primeira queria saber se era teatro para a escola toda e a segunda mostrou-se um pouco revoltada. Ela perguntou qual a idade das crianças que estávamos dando aula. Ao saber que era os de quatro anos soltou um desabafo: "Engraçado, quando os meninos da minha turma tinham quatro anos vocês fizeram o projeto com os de cinco e agora que estou com a turma de cinco anos vocês estão com a turma de quatro" (Charles - Caderno de campo).

Ao questionar a idade das crianças participantes das aulas de teatro, a professora pontuou outro fator importante, a falta de oportunidade das outras crianças terem acesso a projetos oriundos da universidade. Como meu intuito tem sido priorizar apenas uma turma por ano, a fim de estreitar os laços afetivos com as crianças e promover o aperfeiçoamento da docência por parte dos licenciandos, promover aulas de teatro com várias turmas cairia no desgaste de permanecer só na prática, sem o tempo necessário para reflexão - tão necessária ao processo de formação docente. Cogito também que desenvolver uma prática relevante em teatro com apenas uma 
turma pode ser uma estratégia para que, ao perceber que o teatro contribui de forma singular para a formação da criança, a escola incorpore em seu currículo a especificidade da linguagem teatral, contratando um profissional ou capacitando as professoras para o desenvolvimento da linguagem teatral.

Como ofertar aulas de teatro para todas as turmas não era nosso intuito, promover aulas em espaços abertos, tendo a criança como protagonista da ação teatral fazia parte de nosso repertório. Assim foi finalizada a última aula do primeiro semestre daquele ano no pátio da escola. Após as crianças experimentarem o tempo em seus corpos, verem fotos de pessoas de varias idades e buscarem um corpo para aqueles rostos, discutirem sobre quem é mais novo ou mais velho, foi proposto que os pequenos encaminhassem até o pátio da escola para desenhar com giz branco a sua linha do tempo.

Não precisou de nenhum esforço dos adultos para a aderência da proposta pelas crianças, tal como relata Charles:

Para finalizarmos, pedimos para que cada um desenhasse sua linha do tempo no pátio da escola. Demos metade de um giz branco para cada um e o liberamos para desenharem. Pedimos também que após o desenho pudessem ir para a sala de aula, pois já estava chegando ao fim a aula de teatro. Surgiram desenhos de todos os tipos, como por exemplo, uma máquina do tempo feita pela Mayara (Charles - Caderno de campo).

O ensaio realizado pelos adultos no ambiente foi tornando-se rotina na escola. O convívio com a criação teatral começou a acontecer de forma a trazer um respiro para as práticas educativas presentes na UMEI. As crianças que passavam pelo espaço do ensaio quando este acontecia estavam ali por diversos motivos. Algumas delas eram espectadoras assíduas, trazidas por suas professoras. Também aquelas que passavam pelo local para se deslocarem até outro ponto da UMEI e paravam para ver o ensaio. E outras ainda que estavam no tempo escolar destinado à brincadeira livre e iam acompanhar os ensaios. Bruno traz essa percepção:

No começo, não tínhamos lugar definido pra ensaiar. Até que chegamos ao espaço de arena. A partir daí sempre ensaiávamos ali mesmo nos dias depois das aulas. E isso já era muita coisa para as crianças que ali passavam. Algumas vezes, estavam só de passagem e acabavam sentando. Outras estavam lá pra brincar, mas o ensaio lhes chamava a atenção, então observavam, riam, se divertiam. Algumas turmas eram plateia constante (Bruno - Caderno de campo).

Aos poucos, fomos percebendo que essa proposta, até então bastante simples para as pessoas de teatro, revelou-se transformadora para o contexto escolar, que se convertia em um espaço rico de poéticas teatrais, povoadas com sonoridades e corpos não-cotidianos.

Gabriella revelou suas impressões sobre o impacto que os ensaios trouxeram para a escola, como se o teatro, tivesse se tornado parte dela. A escola interferindo na elaboração da cena. Os modos de criação da cena desnudados ao espectador. Jogo, improviso, processo e elaboração eram marcas dos ensaios que aconteceram na UMEI. 
O teatro que invade a escola. A escola que atravessa a cena. As crianças que acompanham o que novamente se repete. Terças e quintas pela manhã. Manhãs de encontros e reencontros. A areia do parquinho que se esconde entre nossos pés descalços. Bastões. Cantos. Lembranças de infância. Tempos de criança. $\mathrm{O}$ tempo da criança. Cantigas. De ninar ou de brincar bem acordado em roda? Cantiga que lembra infância que lembra lugares que lembra dança que lembra roda que lembra amigos antigos que lembra escola. Ocupamos vários de seus lugares. Deixamo-nos afetar pelo seu colorido e por seus brinquedos, pouco usados por adultos, mas repleto de marcas das crianças. Essas que deixam olhares por onde passam. Deixam pistas que por lá e cá tiveram. Observam-nos sem medo de olhar e, por vezes, passam em plena correria de criança sem se deixar dispersar por um fazer adulto. Mas adultos fazem isso? Brincam? Correm? Cantam juntos em roda? Arriscam-se a brincar de pega? (Gabriella - Caderno de campo).

O questionamento sobre o modo como a criança vê o adulto é rico em detalhes. A licencianda-atriz está atenta ao processo de criação do qual é parte, ao mesmo tempo em que se pergunta sobre a relação com o espectador. Gabriella revela nesse ato uma capacidade de professora-artista, sem perder de vista um ou outro aspecto: a criação e a relação com o espectador-criança, dialogando sua produção artística no ambiente escolar.

Em seu mesmo relato, Gabriella pontua:

Mas por que paravam para nos ver? O que fazia daquele experimento algo interessante para ser visto, para merecer uma dedicação de tempo, uma pausa nas atividades diárias e corriqueiras para ver aquela movimentação na arena? Ao longo das semanas fomos estreitando nossa relação com as crianças-espectadoras. Começamos a sentir falta destas quando, por algum motivo, não estavam presentes. Havia ocorrido algo errado? Cansaram de ver o que várias vezes já viram? Perderam o interesse? Está desinteressante? Não. Estavam por ali. Assim como nós. Em percurso, em movimento. Na travessia (Gabriella - Caderno de campo).

Por fim, a cena foi apresentada a toda escola, fazendo valer o princípio de que o teatro tornou-se parte da escola e os licenciandos incorporados como professores -artistas dentro do espaço da Educação Infantil.

\section{Dizeres "em suspenso"}

Se a possibilidade de sair da universidade para encontrar o outro e junto dele descobrir teatralidade era o interesse primeiro dessa proposta, digo que os licenciandos superaram os limites da aprendizagem previstos por mim. Em seus relatos individuais sobre a experiência com as crianças, vários levantaram a dúvida do que pode ser o teatro, já que não precisaram realizar ações que, até então, eram tidas como essenciais a toda aula de teatro, tais como: ocupar o espaço vazio, alongar o corpo, aquecer a voz, realizar jogos corporais, de improviso etc.

Buscar estados de teatralidade junto das crianças foi experienciar teatro? E o que foi o ato de promover a aprendizagem da docência? Estar atento às demandas do outro, do seu modo de expressar, seus anseios e experiências anteriores é propor ao corpo um estado de alerta às diferenças e ao refazer, replanejar-se, exercício de desconstrução necessário ao ofício e à aprendizagem da docência.

A imersão do licenciando tanto na sala de aula com propostas de criação cênica 
para as crianças, quanto no espaço da arena com ensaios semanais trouxe um estado de pertencimento do teatro à escola, sem precisar ter dia e horário para acontecer tal como em eventos nas festividades escolares. $O$ teatro esteve na escola, mostrouse como parte dela e compôs o currículo escolar.

Outro fator que constatamos com essa experiência é a capacidade de exercitar o teatro na educação sem dicotomia entre ensino e criação, visto que as práticas com as crianças ocorriam a partir e influenciando o que era experimentado pelos adultos.

Concluímos entendendo a necessidade da parceria com a escola para a formação do professor de teatro juntamente com o estabelecimento de um espaço para que o teatro se faça presente no cotidiano escolar, fazendo parte do processo de formação estética.

\section{Referências}

BUENO, Kátia Maria Penido. As habilidades humanas: formas de compreensão e processos de constituição. Belo Horizonte, 2000. Dissertação (Mestrado). Faculdade de Educação, Universidade Federal de Minas Gerais.

FIGUEIREDO, Ricardo Carvalho de. Percursos de aprendizagem da docência em teatro a partir do próprio ato docente. Belo Horizonte, 2014. Tese (Doutorado). Escola de Belas Artes, Universidade Federal de Minas Gerais.

LAVE, Jean \& WENGER, Etienne. Aprendizaje situado: participación periférica legítima. Universidad Nacional Autônoma de México. Estado de México, México, 2003.

PUPO, Maria Lúcia. Alteridade em cena. In: Sala Preta - Revista do Programa de PósGraduação em Artes Cênicas. São Paulo, USP, no 12, vol. 1, 2012.

VINCENT, Guy; LAHIRE, Bernard; THIN, Daniel. Sobre a história e teoria da forma escolar. Educação em Revista. Belo Horizonte, n.33, jun. 2001.

Recebido em: 18/08/2015

Aprovado em: 28/06/2016 